\title{
Effects of the lipid peroxidation product $(E)$-4-hydroxy-2-nonenal on ram sperm function
}

\author{
D. P. Windsor ${ }^{1 *}$, I. G. White ${ }^{1}$, M. L. Selley ${ }^{2}$ and M. A. Swan ${ }^{3}$ \\ Departments of ${ }^{1}$ Veterinary Physiology and of ${ }^{3}$ Histology and Embryology, University of Sydney, \\ NSW 2006, Australia; and ' Division of Clinical Sciences, The Australian National University, \\ Woden Valley Hospital, Garran, ACT 2605, Australia
}

(E)-4-hydroxy-2-nonenal (HNE) is a lipid peroxide end-product which exerts powerful biological effects in a variety of cell and tissue systems. The effects of exogenous $\mathrm{HNE}$ on ram spermatozoa were examined in vitro. HNE inhibited the motility of diluted ram spermatozoa in a dose-dependent $\left(100-400 \mu \mathrm{mol} 1^{-1}\right)$ manner $(P<0.05)$. The extent of motility loss varied with sperm concentration as well as with $\mathrm{HNE}$ concentration, and was manifested as a progressive decrease in mean sperm velocity. The suppressive effect of $250-500 \mathrm{mmol} \mathrm{HNE}$ $\mathrm{I}^{-1}$ on the motility of reactivated ram sperm models $(P<0.05)$ was prevented by the addition of $1 \mathrm{mmol}$ reduced glutathione $\mathrm{l}^{-1}$ to the reactivation medium, suggesting that HNE inhibits ram sperm motility via oxidation of sulfhydryl groups in the axoneme. Oxygen uptake by ram spermatozoa was inhibited $(P<0.05)$ by the addition of 100 or $200 \mu \mathrm{mol}$

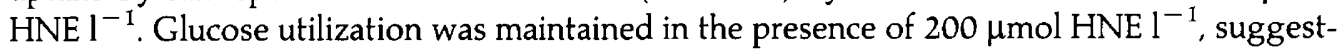
ing that fructolysis was unaffected by HNE. As was the case with motility, the inhibition of oxidative metabolism by HNE was not reversed by washing the spermatozoa. The activity of ram sperm acrosomal enzymes released by cold shock, as measured by hydrolysis of $N$ benzoyl-DL-arginine $p$-nitroanilide (BAPNA), was reduced in the presence of $100 \mu \mathrm{mol} \mathrm{HNE}$ $1^{-1}(p<0.05)$. No evidence was found of disruption of the acrosomal outer membrane or the sperm plasma membrane as a result of exposure to HNE. The effects of HNE on the motility, oxidative metabolism and enzyme activity of ram spermatozoa are in keeping with the effects of lipid peroxides on spermatozoa, and of HNE in other biological systems, reported elsewhere. The lack of membrane disruption by HNE is surprising, given the ability of exogenous peroxide mixtures to disrupt sperm membranes, and the powerful haemolytic activity of HNE.

\section{Introduction}

Aerobic incubation of mammalian or avian spermatozoa is typically associated with a deterioration of motility and metabolic function (review by Mann and Lutwak-Mann, 1981). Jones and Mann (1973) pointed out that analogous changes could be induced in somatic cells by lipid peroxidation and demonstrated the accumulation of a peroxidation product (malonaldehyde) by ram spermatozoa in vitro.

The effects of endogenous or exogenous lipid peroxides on ram spermatozoa include irreversible loss of motility, inhibition of fructolysis and respiration, leakage of intracellular enzymes and structural damage to the plasma membrane (Jones and Mann, 1976, 1977a, b). Motility loss due to fatty acid peroxides has also been noted in spermatozoa of boars, rats, stallions (Jones and Mann, 1977a), humans (Jones and Mann, 1977a; Jones et al., 1979; Diezel et al., 1980), rabbits (Jones and Mann, 1977a; Alvarez and Storey, 1982), bulls (Jones and Mann, 1977a; Slaweta et al., 1988), roosters (Fujihara and Howarth,

*Present address: Sheep Industries Branch, Great Southern Agricultural Research Institute, Katanning, WA 6317, Australia.

Received 20 October 1992.
1978) and mice (Alvarez and Storey, 1984b). Severe plasma membrane damage has also been ascribed to peroxidation of membrane lipids in rabbit (Alvarez and Storey, 1984a) rooster (Fujihara and Koga, 1984) and bull (Slaweta et al., 1988) spermatozoa. Exposure to peroxidized lipids has been associated with a decline in the fertilizing capacity of rooster spermatozoa, even at concentrations that are too low to impair motility (Wishart, 1984). Increased production of free radicals by human spermatozoa has been linked to decreased ability to penetrate oocytes, and peroxidation has been proposed as a likely mechanism (Aitken and Clarkson, 1987).

In light of the observation that peroxidation and free radical production are most active in damaged or less motile spermatozoa (Jones and Mann, 1973, 1977b; Jones et al, 1978, 1979; Aitken and Clarkson, 1988; Slaweta et al., 1988), it seems likely that peroxidation is a factor in the toxic effects that such spermatozoa have been shown to exert on healthier spermatozoa (Shannon, 1965; Shannon and Curson, 1972; Sexton, 1988). This contention and the role proposed for lipid peroxides in sperm senescence by Jones and Mann (1973) suggests that management of peroxidation is an important consideration when preparing spermatozoa for long term storage. 
The hydroxyalkenals are among the most plentiful (Esterbauer et al., 1982) and toxic products of biological peroxidation. Although these compounds have been examined for their effects on a variety of tissues, notably in the liver (reviewed by Comporti, 1985), their influence on spermatozoa has largely escaped scrutiny. A number of their effects have the potential to play a role in lipid peroxidation damage to spermatozoa. Membrane damage (Benedetti et al., 1977, 1979; Roders et al., 1978), for instance, leads to motility loss and impaired acrosomal function. Inhibition of adenylyl cyclase (Paradisi $e t$ al., 1985) prevents synthesis of cyclic AMP, which plays an important role in flagellar motility (Mann and Lutwak-Mann, 1981). The reactivity of aldehydic peroxides with the free sulfhydryl groups of tubulin (Gabriel et al., 1983, 1985) suggests that the axoneme is directly inhibited, via its microtubular components. Even if motility were maintained, and fertilization unimpaired by acrosomal lysis or inhibition of acrosomal enzymes, the spermatozoa could still be rendered ineffective by the direct effects of hydroxyalkenals on the genome (Brambilla et al., 1986; Griffin and Segall, 1986; Winter et al, 1986).

One of the most plentiful (Benedetti et al., 1980; Poli et al., 1985) and cytotoxic (Cadenas et al., 1983) hydroxyalkenals is $(E)$-4-hydroxy-2-nonenal (HNE). The presence of HNE has been demonstrated in human semen, as has its ability to abolish motility in human spermatozoa (Selley et al., 1991). The aim of the following experiments was to observe the effects of exogenous HNE on ram spermatozoa in vitro, and to examine these in the light of previous reports of lipid peroxide intoxication of spermatozoa.

\section{Materials and Methods}

\section{Preparation and assessment of sperm suspensions}

Semen was collected from mature Merino rams by electroejaculation, and its quality assessed on a scale from 0 to 4 as described by Emmens (1947). Precautions were taken to prevent cold shock to spermatozoa during collection or storage. Spermatozoa were counted in a haemocytometer (sperm concentrations typically ranging from $2 \times 10^{9}$ to $4 \times 10^{9}$ spermatozoa $\mathrm{ml}^{-1}$ ). Semen was diluted to the desired sperm concentration by addition of warmed Krebs-Ringer phosphate solution (Umbreit $e t$ al., 1959) containing 0.1\% glucose (KRPG).

Motility of experimental samples assessed under light microscopy was scored on a scale of 0 to 4 , including half values. A drop of sperm suspension was placed on a microscope slide under a coverslip and examined on a warm stage at $37^{\circ} \mathrm{C}$. A motility index (1-100) was produced by multiplying this score by the estimated percentage of motile spermatozoa present in the sample, and dividing the product by four.

\section{Preparation of HNE}

HNE was supplied as a stock solution (approximately $70 \mathrm{mmol} \mathrm{l}^{-1}$ ) in chloroform. Aqueous solutions of HNE for experimental purposes were prepared as follows. A $50 \mu \mathrm{l}$ aliquot of stock solution was transferred to a $10 \mathrm{ml}$ glass centrifuge tube and gently agitated until the chloroform evaporated, leaving a few small droplets of HNE. These droplets were dissolved by the addition of $500 \mu \mathrm{l}$ of the appropriate buffer, covered and vortexed for $30 \mathrm{~s}$. The HNE concentration of the resulting solution was determined by UV spectrophotometry as described by Selley et al. (1988).

\section{Photographic measurement of velocity of ram spermatozoa}

The swimming velocity of ram spermatozoa was determined by the stroboscopic technique described by Molinia and Swan (1991). Spermatozoa were diluted to a final concentration of $2 \times 10^{7} \mathrm{ml}^{-1}$ in KRPG, which contained $1 \%$ BSA to prevent agglutination of spermatozoa or adhesion of spermatozoa to glass. A droplet, $12.5 \mu$ l, of sperm suspension was mounted on a cleaned microscope slide, under a cleaned coverslip.

Sperm movement in control and treated samples was recorded on $35 \mathrm{~mm}$ Tri-X film (400 ASA) using 0.5 or I s exposures with a Wild MPS 12 camera. A stroboscope was matched to the tailwave frequency and mounted between a Xenon arc light source (Wild) and a Zeiss WL microscope with a $0.8 / 0.95$ dark field condenser, $40 \times / 0.65$ objective and $16 \times \mathrm{Kpl}$ ocular.

Motility observations were made at room temperature (23$25^{\circ} \mathrm{C}$ ). All observations were made within $3 \mathrm{~h}$ of semen collection.

Velocity $\left(\mu \mathrm{m} \mathrm{s}^{-1}\right)$ was calculated by measuring the net displacement of the sperm head (in $\mu \mathrm{m}$ ) and dividing by the exposure time (in seconds) to give the point-to-point straight line velocity.

\section{Reactivation of ram sperm models}

The techniques for demembranation and reactivation of ram sperm models were based on those of White and Voglmayr (1986) as modified by Vishwanath et al. (1986). Sperm membranes were extracted by pipetting a $100 \mu \mathrm{l}$ aliquot of sperm suspension $\left(1 \times 10^{8} \mathrm{ml}^{-1}\right)$ into $0.9 \mathrm{ml}$ of demembranation medium, consisting of $25 \mathrm{mmol}$ potassium glutamate $1^{-1}$, $0.2 \mathrm{~mol}$ sucrose $\mathrm{l}^{-1}, 1 \mathrm{mmol} \mathrm{MgSO}_{4} \mathrm{I}^{-1}, 2 \mathrm{mmol}$ dithiothreitol $\mathrm{l}^{-1}, \mathrm{I} \mathrm{mmol}$ EGTA $\mathrm{l}^{-1}$, and $0.025 \%(\mathrm{w} / \mathrm{v})$ Triton $X-100$. Spermatozoa were gently agitated for $15 \mathrm{~s}$, and diluted tenfold into a reactivation medium, which had the same composition as the demembranation medium except that Triton $X-100$ was

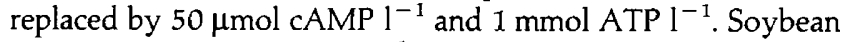
trypsin inhibitor $\left(40 \mu \mathrm{g} \mathrm{ml}^{-1}\right)$ was added to the reactivation medium to reduce ultrastructural damage to sperm models by the acrosomal proteases released at demembranation (Vishwanath et al., 1986).

A drop of sperm suspension from the reactivation mixture was transferred to a $10 \mu \mathrm{m}$ Makler chamber and examined under an Olympus $\mathrm{BH} 2$ light microscope. The proportion of spermatozoa exhibiting tail movement (percentage reactivation) was recorded at regular intervals.

Substances being tested for their effects on the axoneme were added to the reactivation medium before the addition of spermatozoa.

\section{D-glucose and L-lactate analyses}

Spermatozoa were washed twice in Krebs-Ringer phosphate solution containing $0.05 \%(\mathrm{w} / \mathrm{v})$ glucose (to remove endogenous lactate and fructose) before counting and dilution to Downloaded from Bioscientifica.com at 04/26/2023 11:03:17AM 
$1 \times 10^{8}$ spermatozoa $\mathrm{ml}^{-1}$. The spermatozoa were then incubated at $30^{\circ} \mathrm{C}$ with $\operatorname{HNE}\left(0,100\right.$ or $\left.200 \mu \mathrm{mol} \mathrm{I}^{-1}\right)$. Immediately, and at 1,2 and $3 \mathrm{~h}$ after the addition of HNE, a $1 \mathrm{ml}$ aliquot of sperm suspension was deproteinized with $1 \mathrm{ml} 0.3 \mathrm{M} \mathrm{Ba}(\mathrm{OH})_{2}$ and $1 \mathrm{ml} 5 \%(\mathrm{w} / \mathrm{v}) \mathrm{ZnSO}_{4} \cdot 7 \mathrm{H}_{2} \mathrm{O}$. The resulting suspension was centrifuged at $500 \mathrm{~g}$ for $15 \mathrm{~min}$. The supernatant was removed, and stored at $-20^{\circ} \mathrm{C}$ until required for glucose and lactate determination. D-Glucose and L-lactate concentrations were measured enzymically as described by Bergmeyer et al. (1974) and Gutman and Wahlefeld (1974).

\section{Measurement of oxygen uptake by spermatozoa}

Spermatozoa were diluted in KRPG to a concentration of $1 \times 10^{8}$ spermatozoa $\mathrm{ml}^{-1}$, and their rate of respiration at $30^{\circ} \mathrm{C}$ was measured with an oxygen electrode (Rank Bros., Cambridge, UK). Oxygen uptake $\left(\mu 11^{-8}\right.$ spermatozoa $h^{-1}$ ) was determined from the slope of the chart recorder trace of the electrode.

\section{Measurement of amidase activity of spermatozoa}

The effect of HNE on acrosomal enzymes was compared by measurement of sperm-bound amidase activity. This technique monitors hydrolysis of $N$-benzoyl-DL-arginine $p$-nitroanilide (BAPNA), a synthetic chromogenic substrate of trypsin-like enzymes (Froman et al., 1984, 1987). The activity of such enzymes in spermatozoa is restricted to the acrosome (Yanagimachi and Teichman, 1972). Lysis of the acrosomal membrane releases proteases which hydrolyse the amide bonds present in BAPNA, resulting in a colour change. The product of this reaction is detectable at $410 \mathrm{~nm}$, and its concentration is directly proportional to the level of proteolytic enzyme activity in the suspending medium.

Ram spermatozoa were diluted to $1 \times 10^{8} \mathrm{ml}^{-1}$ in KRPG, and incubated at $30^{\circ} \mathrm{C}$ for $90 \mathrm{~min}$ in the presence of 0,100 or $200 \mu \mathrm{mol} \mathrm{HNE} 1^{-1}$. Spermatozoa were then divided into $1.5 \mathrm{ml}$ aliquots, half of which were cold shocked to disrupt the acrosomal plasma membrane.

Amidase activity was determined by the addition of $0.5 \mathrm{ml}$ of $2.5 \mathrm{mmol}$ BAPNA $\mathrm{I}^{-1}$ in KRP containing $0.3 \%$ polyvinyl alcohol. After incubation for $30 \mathrm{~min}$ at $30^{\circ} \mathrm{C}$, further amidase activity was inhibited by the addition of $0.5 \mathrm{ml}$ of $50 \mathrm{mmol}$ benzamidine $l^{-1}$ in KRP. Spermatozoa were pelleted by centrifugation ( $15 \mathrm{~min}, 500 \mathrm{~g}$ ), and $1.5 \mathrm{ml}$ of supernatant was diluted 1:1 in KRP before measurement of its optical density at $410 \mathrm{~nm}$.

\section{Supravital staining of ram spermatozoa}

The proportion of spermatozoa with intact plasma membranes was judged on the basis of their ability to exclude eosin (Hancock, 1951). Sperm suspensions were diluted fivefold in eosin-nigrosin stain, and thin films prepared on precleaned slides. Smears were air dried, and examined by bright field microscopy. Two-hundred spermatozoa were examined on each slide, and the relative proportions of stained and unstained cells determined.
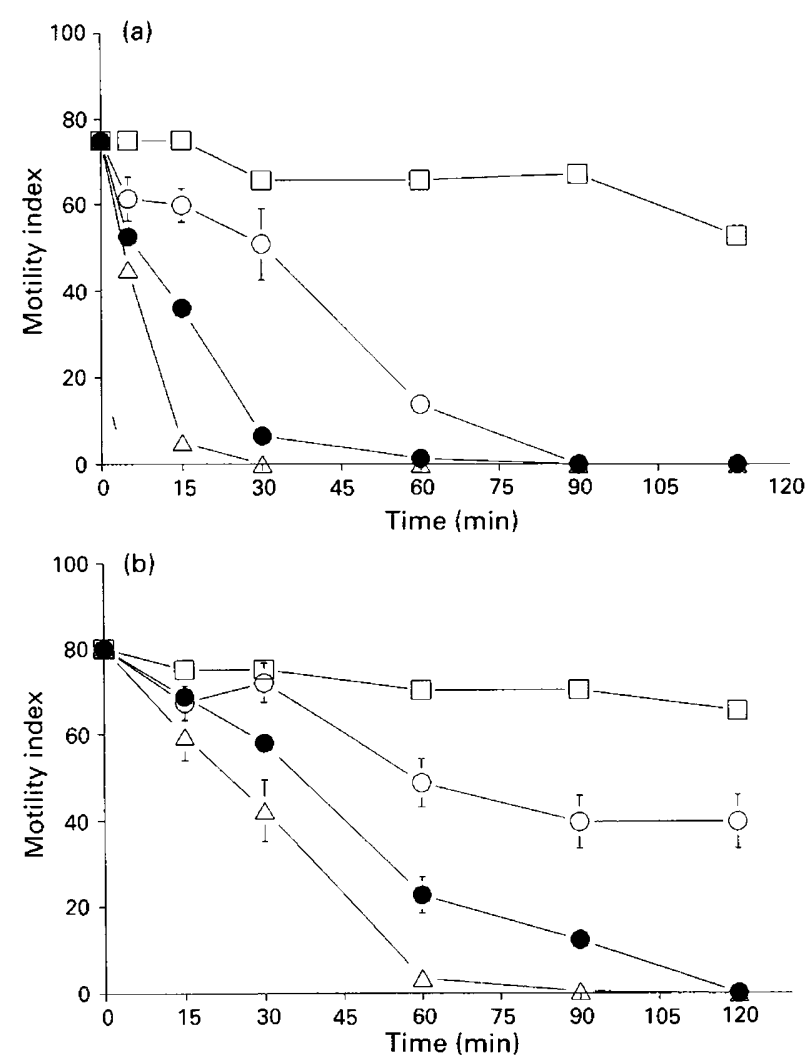

Fig. 1. The effect of incubation with $(\square) 0,(\bigcirc) 100,(\bigcirc) 200$ or $(\triangle)$ $400 \mu \mathrm{mol}(E)$-4-hydroxy-2-nonenal (HNE) $\mathrm{l}^{-1}$ on the motility of fresh ram spermatozoa diluted to (a) $1 \times 10^{7}$ or (b) $1 \times 10^{8}$ spermatozoa $\mathrm{ml}^{-1}$ in Krebs-Ringer phosphate solution containing $1 \%$ glucose (KRPG). Points represent the mean ( \pm SEM) of four observations.

\section{Chemicals}

HNE ((E)-4-hydroxy-2-nonenal) was the gift of H. Esterbauer (University of Graz, Austria). The purity of HNE was confirmed by high performance liquid chromatography. BAPNA, benzamidine, reduced glutathione, cyclic AMP, EGTA, potassium glutamate and soybean trypsin inhibitor were purchased from Sigma Chemicals (St Louis, MO). Hydrazine hydrate was supplied by Ajax Chemicals (Auburn, NSW), and dithiothreitol by Calbiochem (La Jolla, CA). ATP, NAD, NADPH, LDH, glucose6-phosphate dehydrogenase and hexokinase were supplied by Boehringer-Mannheim (Sydney, NSW). All chemicals were of analytical reagent or the highest quality alternative grade.

\section{Statistical analyses}

Data were analysed by analysis of variance. Differences between specific means were determined using either least significant differences or orthogonal contrasts (Steel and Torrie, 1981).

\section{Results}

\section{Effect of HNE on the motility of ram spermatozoa}

The impact of HNE on ram sperm motility is demonstrated (Fig. 1). The reduction in sperm motility during incubation at 


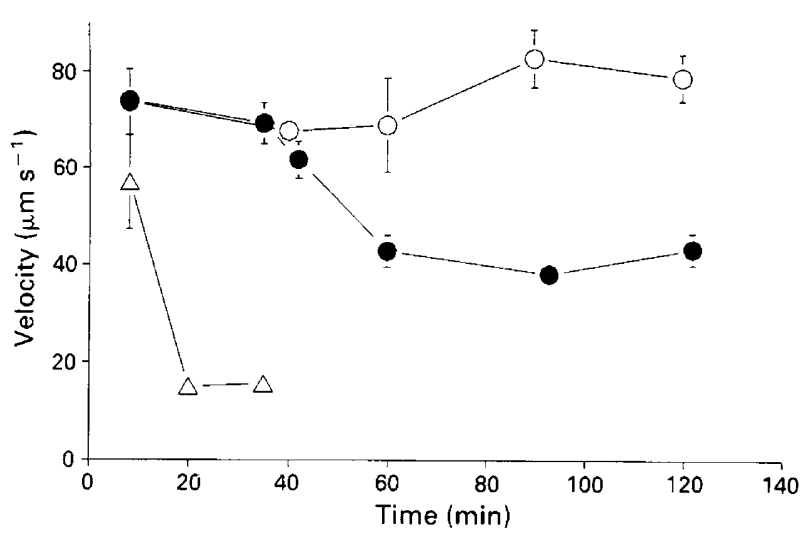

Fig. 2. The effect of $(E)-4$-hydroxy-2-nonenal $(\mathrm{HNE})((O) 0,(\bigcirc) 250$ or $\left.(\triangle) 500 \mu \mathrm{mol} \mathrm{l}^{-1}\right)$ on the velocity of ram spermatozoa $\left(10^{7} \mathrm{ml}^{-1}\right)$ as estimated by strobographic photography. Points represent the mean $( \pm$ SEM) of between three and ten observations.

$30^{\circ} \mathrm{C}$ was clearly dose dependent, and the means corresponding to $0,100,200$ and $400 \mu \mathrm{mol} \mathrm{HNE} \mathrm{l}^{-1}$ all differed significantly $(P<0.01)$. Both the overall effect of $\operatorname{HNE}(P<0.01)$ and the time taken for motility to decline $(P<0.01)$ were also strongly influenced by the concentration of spermatozoa present in the incubation mixture. This was also the case for spermatozoa outside the concentration range $\left(10^{7}-10^{8} \mathrm{ml}^{-1}\right)$ shown. Incubation of $1 \times 10^{6}$ spermatozoa $\mathrm{ml}^{-1}$ with $100 \mu \mathrm{mol} \mathrm{HNE} \mathrm{l}^{-1}$ normally resulted in their complete immobilization within $10 \mathrm{~min}$. However, $1 \times 10^{9}$ spermatozoa $\mathrm{ml}^{-1}$ endured incubation with up to $200 \mu \mathrm{mol} \mathrm{HNE} 1^{-1}$ for $2 \mathrm{~h}$ with no apparent deterioration in their motility.

The motility score (Emmens, 1947) component of the motility index tended to deteriorate more rapidly than the percentage of motile spermatozoa. Substantial increases in the proportion of completely immotile cells did not normally occur until almost all spermatozoa were no longer exhibiting progressive motility.

\section{Effect of HNE on the swimming velocity of ram spermatozoa}

HNE caused a dose dependent decrease in progressive motility velocities of ram spermatozoa $(P<0.05)$ (Fig. 2). After incubation for $45 \mathrm{~min}$ with $500 \mu \mathrm{mol} \mathrm{HNE} \mathrm{l}^{-1}$, all spermatozoa had ceased progressive motility, but the proportion of completely immotile cells was no higher than in the control group.

\section{Effect of HNE on duration of reactivation of ram sperm models}

The influence of 250 or $500 \mu \mathrm{mol} \mathrm{HNE} \mathrm{l}^{-1}$ on the proportion of demembranated ram sperm models showing tail movement (percentage reactivation) after the addition of $1 \mathrm{mmol}$ ATP $1^{-1}$ is shown (Fig. 3a). Both HNE concentrations reduced the duration of reactivation $(P<0.05)$. While addition of $500 \mu \mathrm{mol}$ HNE $1^{-1}$ decreased the initial percentage of sperm models reactivating $(P<0.05)$ in the initial experiment (Fig. 3a), this effect was not apparent in the subsequent experiment (Fig. 3b). Duration of reactivation appears to be longer for control
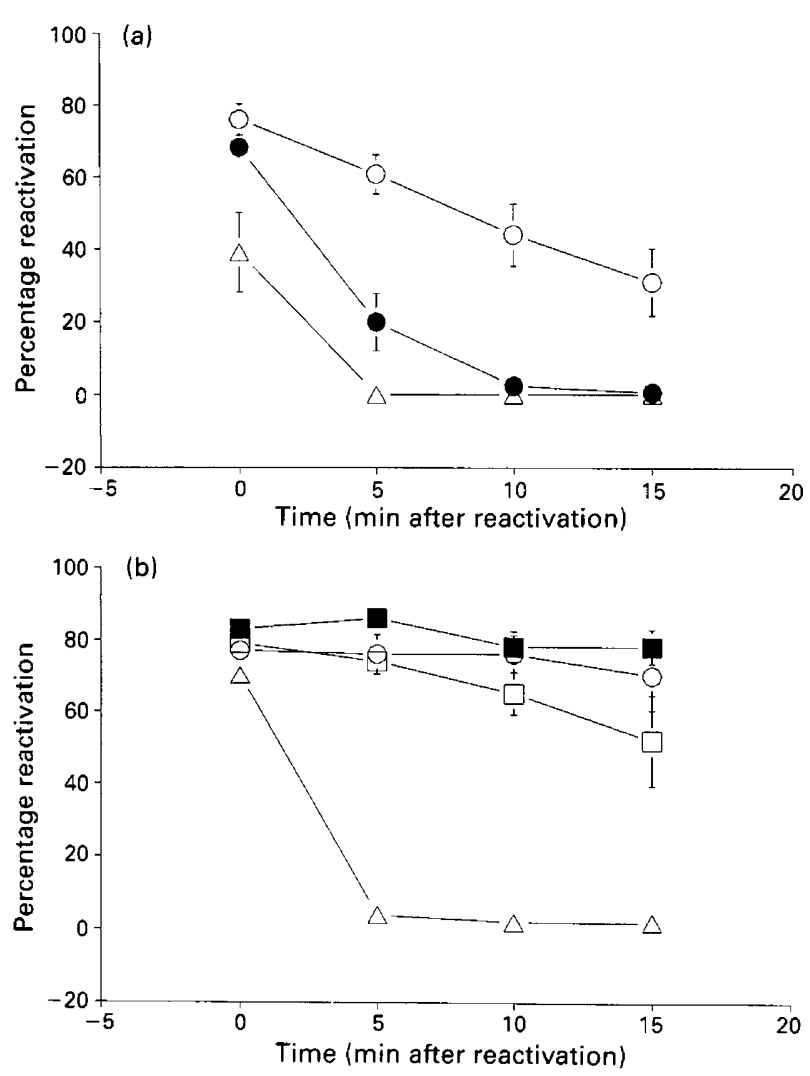

Fig. 3. (a) The effect of $(E)-4$-hydroxy-2-nonenal (HNE) ((O) 0 , 250 or $(\triangle) 500 \mu \mathrm{mol} \mathrm{l}^{-1}$ ) on the duration of reactivation of ram sperm models and (b) the protective effect of $1 \mathrm{mmol}$ reduced glutathione $1^{-1}$ (ם) control plus glutathione; ( $\square$ ) $500 \mu \mathrm{mol} \mathrm{HNE} \mathrm{l}^{-1}$ plus glutathione. Points represent means ( \pm SEM) of four observations.

spermatozoa in Fig. 3b than Fig. 3a, possibly owing to variation between the pooled ejaculates used in the two experiments.

Addition of $1 \mathrm{mmol}$ reduced glutathione $\mathrm{I}^{-1}$ (GSH) to the reactivation medium resulted in a substantial increase in the duration of reactivation of sperm models exposed to $500 \mu \mathrm{mol}$ $\mathrm{HNE} \mathrm{I}^{-1}$ (Fig. 3b). The proportion of reactivated spermatozoa in HNE plus GSH treated spermatozoa did not differ from that of controls.

Effects of HNE on the glycolytic and oxidative metabolism of ram spermatozoa

The influence of 100 or $200 \mu \mathrm{mol} \mathrm{HNE} 1^{-1}$ on oxygen uptake of ram spermatozoa is shown (Fig. 4). Both concentrations of HNE produced a substantial decrease in oxygen uptake $(P<0.05)$ within $30 \mathrm{~min}$. The overall suppression of

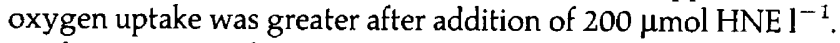

The quantity of glucose present in the $100 \mu \mathrm{mol} \mathrm{HNE} 1^{-1}$ samples was consistently lower than in the controls $(P<0.05$; Fig. 5a). This was probably due to lower initial concentrations of glucose, as there was no interaction effect between treatments and time to suggest any difference in the rate of glucose utilization.

Overall lactate accumulation was lower in control spermatozoa than in those exposed to 100 or $200 \mu \mathrm{mol} \mathrm{HNE} 1^{-1}$ Downloaded from Bioscientifica.com at 04/26/2023 11:03:17AM 

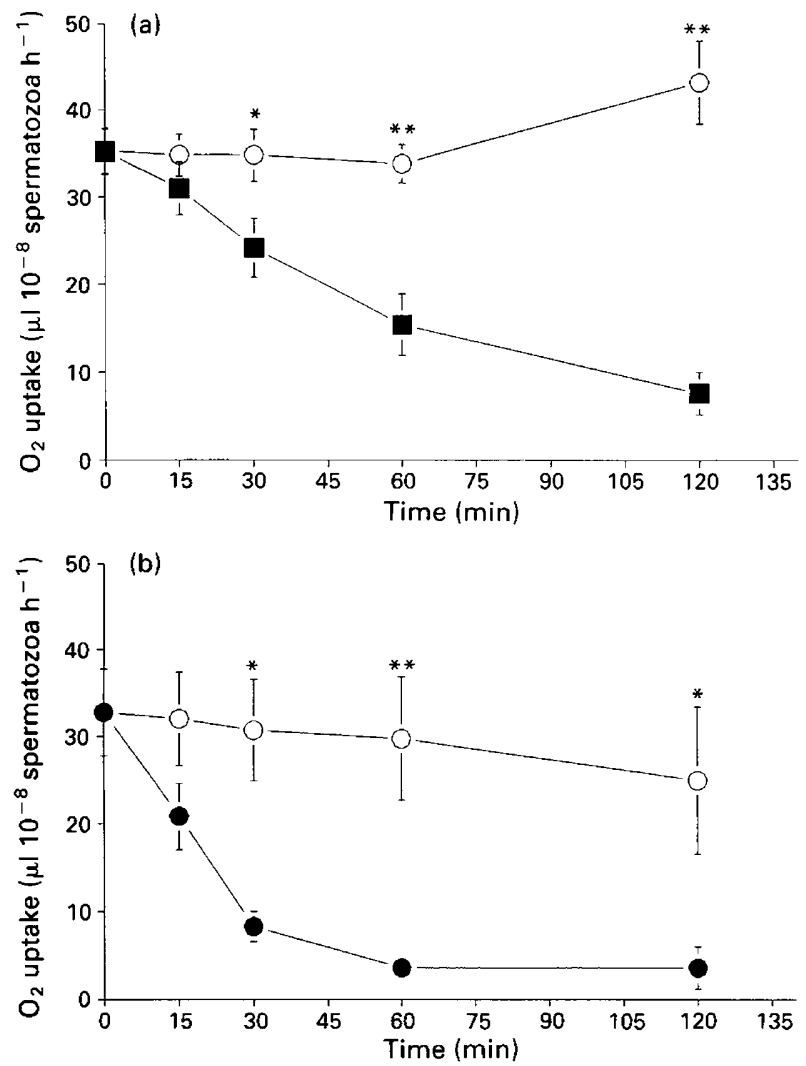

Fig. 4. Inhibition of oxygen uptake of ram spermatozoa by (a) ( $\boldsymbol{\square}) 100$ or (b) (O) $200 \mu \mathrm{mol}(E)$-4-hydroxy-2-nonenal (HNE) $1^{-1}$ compared with (O) controls. Points represent means $( \pm \mathrm{SEM})$ of four observations $\left({ }^{*} P<0.05 ;{ }^{* *} P<0.01\right)$.

$(P<0.05$; Fig. $5 b)$. The interaction between HNE concentration and time was also significant $(P<0.05)$, suggesting that lactate concentrations increased more rapidly in the presence of HNE.

\section{Effect of washing on ram spermatozoa pretreated with $H N E$}

After addition of $200 \mu \mathrm{mol} \mathrm{HNE} \mathrm{l}^{-1}$ to sperm suspensions $\left(1 \times 10^{8} \mathrm{ml}^{-1}\right)$, incubation for $60 \mathrm{~min}$ and washing spermatozoa twice in ten volumes of KRPG to reduce the concentration of HNE, the inhibitory effects of HNE on either motility or oxygen uptake were not reversed (Fig. 6).

When a sperm suspension $\left(1 \times 10^{9}\right.$ sperm $\left.\mathrm{ml}^{-1}\right)$ was centrifuged $(15 \mathrm{~min}, 500 \mathrm{~g}$ ) after incubation for $2 \mathrm{~h}$ with $250 \mu \mathrm{mol}$

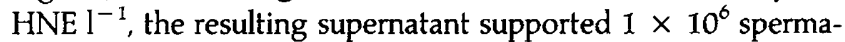
tozoa $\mathrm{ml}^{-1}$ with no observable effect on motility over $30 \mathrm{~min}$. Dilution of spermatozoa $\left(1 \times 10^{6} \mathrm{ml}^{-1}\right)$ with a $250 \mu \mathrm{mol} \mathrm{I}^{-1}$ solution of the same batch of HNE abolished all motility within $5 \min (n=3)$.

\section{Effect of HNE on amidase activity of ram spermatozoa}

The amidase activity detectable in intact ram spermatozoa after 90 min exposure to HNE was lower $(P<0.01)$ than that of cold shocked spermatozoa, and was not altered by HNE (Fig. 7). The amidase activity in cold shocked spermatozoa was
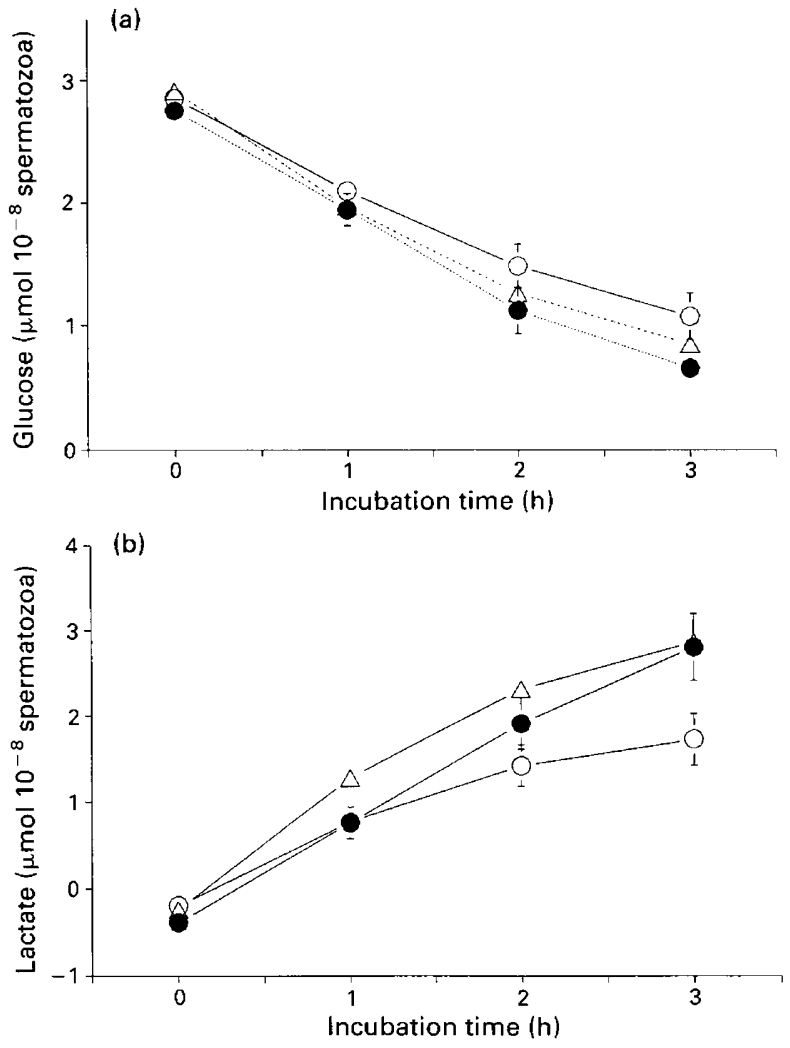

Fig. 5. The effect of $(\bigcirc) 0,(O) 100$ or $(\triangle) 200 \mu \mathrm{mol}(E)$-4-hydroxy-2nonenal (HNE) $l^{-1}$ on (a) glucose utilization and (b) lactic acid accumulation by ram spermatozoa $\left(10^{8} \mathrm{ml}^{-1}\right)$. Points represent means $( \pm \mathrm{SEM})$ of four observations.

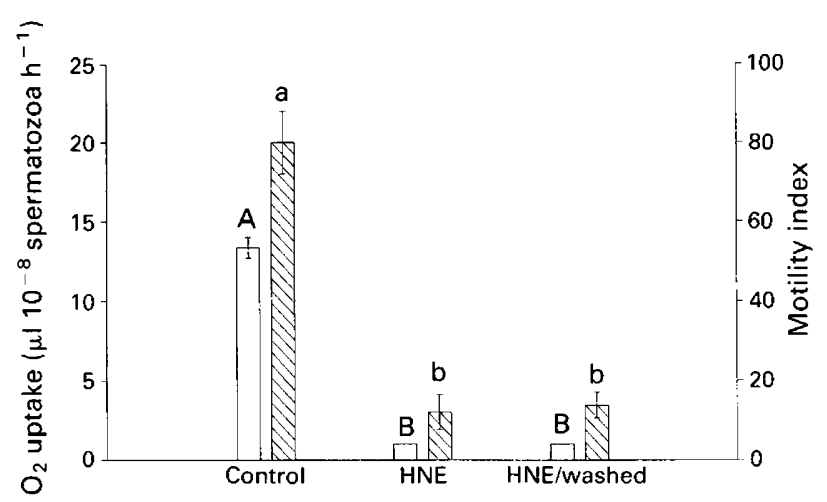

Fig. 6. The effect of removal of (E)-4-hydroxy-2-nonenal (HNE) $\left(200 \mu \mathrm{mol} \mathrm{l}^{-1}\right)$ by washing twice in Krebs-Ringer phosphate solution containing 1\% glucose (KRPG) after $60 \mathrm{~min}$ exposure on ( $\square$ ) the motility and ( $\mathbb{Q}$ ) oxygen uptake of ram spermatozoa $\left(10^{8} \mathrm{ml}^{-1}\right)$. Bars represent means $( \pm \mathrm{SEM})$ of three observations. Bars with different superscripts are significantly different $(P<0.01)$.

reduced by either 100 or $200 \mu \mathrm{mol} \mathrm{HNE} \mathrm{I}^{-1}(P<0.05)$. No difference in sperm bound amidase activity was detected between spermatozoa subjected to the two concentrations of HNE. 


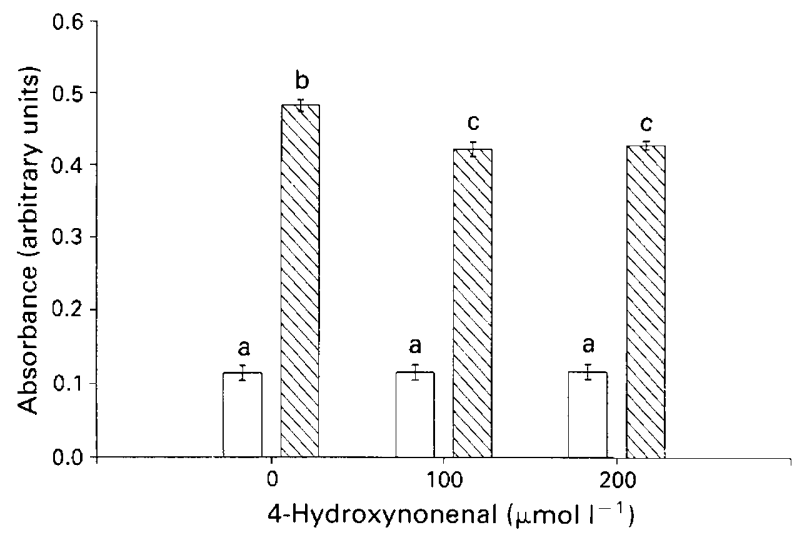

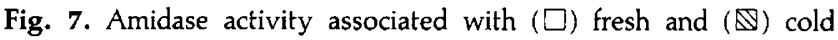
shocked ram spermatozoa $\left(10^{8} \mathrm{ml}^{-1}\right)$ pretreated for 90 min with $(E)-4$ hydroxy-2-nonenal (HNE). Bars show means ( \pm SEM) of three observations. Bars with different superscripts are significantly different $(a-b$ : $P<0.05$; b-c: $P<0.01$ ).

\section{Effect of HNE on the ability of ram spermatozoa to exclude eosin}

Ram spermatozoa $\left(10^{8} \mathrm{ml}^{-1} ; n=3\right)$ were incubated for $1 \mathrm{~h}$ in the presence or absence of $400 \mu \mathrm{mol} \mathrm{HNE} 1^{-1}$. The substantial decline in mean $( \pm$ SEM) sperm motility index over this period, from $65.6 \pm 2.5$ to $8.3 \pm 3.1$, was not accompanied by a decrease in the proportion of unstained spermatozoa. The mean proportions of unstained spermatozoa before and after incubation with HNE were $80.4 \pm 1.6 \%$ and $83.7 \pm 3.3 \%$, respectively.

\section{Discussion}

The motility of both intact and demembranated ram spermatozoa and of washed human spermatozoa was inhibited by (E)-4hydroxy-2-nonenal in a dose-dependent manner. Oxidation of sulfhydryl (-SH) groups by HNE and related compounds has been demonstrated in microtubular protein (Gabriel et al., 1983, 1985) and low density lipoproteins (Jürgens et al., 1986). HNE also binds the thiol groups of sulfur-bearing amino acids (Esterbauer et al., 1976), which suggests that HNE inhibits sperm motility by reacting with the free sulfhydryl groups of the axonemal microtubules. The observation that motility loss was characterized by a steady decline in the vigour and velocity of motility throughout the population of spermatozoa, rather than abrupt cessation of movement by individual spermatozoa, is consistent with a steadily increasing inhibition of the axoneme. Further evidence for this hypothesis is provided by the observation that providing an alternative source of $-\mathrm{SH}$ groups (in this case reduced glutathione) reduces the severity of HNE-induced motility loss. HNE-induced chemiluminescence in hepatocytes depends on the quantity of HNE present exceeding that of glutathione, as the two compounds react in a $1: 1$ ratio (Cadenas et al., 1983).

The presence of $1 \%$ serum albumin in the suspending medium (compare the effects of HNE on motility in Fig. 2 and Fig. 1a) also appeared to provide some protection against HNE. This may well be because the propensity of HNE for reacting with the thiol (Esterbauer et al., 1976) or amino (Jürgens et al., 1986) groups of amino acids, thereby reducing the quantity of HNE available to react with axoneme. The inverse relationship between sperm concentration and the rapidity and severity of HNE induced motility loss is presumably due to the reduced ratio of HNE to microtubular protein. Residual seminal plasma may also provide more protection at lower dilution rates, although Jones and Mann (1977b) found that ram seminal plasma offered little defence against peroxide toxicity. The observation that an HNE solution exposed to spermatozoa is subsequently incapable of immobilizing a second sperm sample, in a similar manner to peroxidized arachidonic acid (Jones and Mann, 1977a), suggests that the reaction of HNE with sperm tubulin is, like that from other tissues, largely irreversible (Gabriel et al., 1985).

Repeated washing with fresh buffer failed to reverse the effects of HNE on either the motility or metabolism of ram spermatozoa. This finding is consistent with the observation that hydroxyalkenals react with thiols to form cyclic hemiacetals, the stability of which render the reaction largely irreversible (Esterbauer et al, 1975), and the high affinity of HNE for membrane lipids. Jones and Mann (1977a, b) also observed that the disruption of ram sperm function by lipid peroxides could not be reversed by washing.

The results presented above offer no evidence for the inhibition of ram sperm fructolysis by HNE. The rate of glucose utilisation in HNE-treated spermatozoa did not differ from that of controls. Further evidence of continued glycolytic activity is provided by the observation that spermatozoa maintained progressive motility under conditions in which oxygen uptake was reduced by over $90 \%$ (compare the effects of $200 \mu \mathrm{mol} \mathrm{HNE}$ $1^{-1}$ in Figs $\mathrm{Ib}$ and $4 \mathrm{~b}$ ). This result is in contrast to the observation that exposure to both exogenous and endogenous lipid peroxide products irreversibly abolished fructolytic activity in ram spermatozoa (Jones and Mann, 1977a,b). This may be due to the fact that peroxidation induced by UV light or iron catalysis (as in the earlier studies) produces many toxic substances other than 4-hydroxyalkenals. Glycolytic inhibition may therefore be due to peroxidation products other than HNE, or require a higher concentration of total inhibitory substances than were used in the study reported here.

Oxygen uptake by ram spermatozoa was reduced in a dosedependent manner in the presence of HNE. The increased rate of accumulation of lactic acid by HNE-treated spermatozoa indicates a decrease in activity of the TCA cycle. Whether this is the result of direct TCA cycle inhibition, or a consequence of endproduct accumulation resulting from inhibition of the respiratory chain cannot be determined from the current data. The observed inhibition of respiration is concurrent with the effect of lipid peroxides on ram spermatozoa (Jones and Mann, $1977 \mathrm{a}, \mathrm{b}$ ) and other mammalian tissues (reviewed by Barber and Bernheim, 1967).

The amidase activity associated with cold shocked ram spermatozoa was reduced by the addition of HNE. While an inhibition of acrosin by HNE would parallel the inhibition of membrane bound enzymes by peroxidized lipids (Roubal and Tappel, 1965; Wills, 1971) or HNE in a number of other tissues (Ferrali et al., 1980; Paradisi et al., 1985; Lame and Segall, 1987), the small decrease in amidase activity observed that was not dose dependent may not be due to direct effects on the enzyme. Downloaded from Bioscientifica.com at 04/26/2023 11:03:17AM 
High concentrations of HNE may affect the enzyme via indirect mechanisms. A possible alternative explanation is that HNE provided a degree of protection to spermatozoa against cold shock. Although the acrosomal plasma membrane has been shown to be particularly susceptible to peroxidation damage (Jones and Mann, 1977a, b), there was no evidence to suggest that incubation with HNE increased the release of acrosomal enzymes from spermatozoa that had not been cold shocked.

Similarly, treatment of spermatozoa with $400 \mu \mathrm{mol} \mathrm{HNE} \mathrm{l}^{-1}$ for $1 \mathrm{~h}$, sufficient to completely abolish motility and respiration, did not increase the proportion of ram spermatozoa stained by eosin. These results together with those for amidase activity (indicating intact acrosomal membranes) suggest that disruption of the sperm plasma membrane by HNE is minimal. This is surprising in light of the widespread effects of peroxidized lipids on a variety of membranes, including those of spermatozoa (Jones and Mann, 1973, 1976, 1977a, b; Alvarez and Storey, 1984a; Fujihara and Koga, 1984; Slaweta et al., 1988). Hydroxyalkenals also produce a number of membrane related phenomena, including lysis of erythrocytes (Benedetti et al,, 1977, 1979; Roders et al., 1978). It is notable, however, that the haemolytic activity of synthetic HNE is less than that of a mixture of the aldehydes produced by peroxidation, although a $450 \mu \mathrm{mol} 1^{-1}$ solution was sufficient to lyse $50 \%$ of erythrocytes present (Comporti et al., 1985). The mechanism by which ram spermatozoa are better able to resist membrane disruption by HNE than are erythrocytes is unknown.

In conclusion, the data presented here indicate that HNE exerts powerful inhibitory effects on the motility and oxidative metabolism of ram spermatozoa. The reactivation studies suggest that the reaction of HNE with thiol groups in the axoneme is an important factor in the inhibition of motility. The nature of the interaction between HNE and sperm respiration has not been determined, but the lack of effect of HNE on the plasma membrane systems examined suggests that enzyme inhibition is a likely cause, possibly via modification of enzymatic thiol or amino groups.

Although it is evident that HNE is toxic to ram spermatozoa in vitro, the concentrations used in this study were $40-$ 200 times the maximum HNE concentrations (approximately $2.7 \mu \mathrm{mol} \mathrm{I}^{-1}$ ) recorded in human semen by Selley et al. (1991). Unless HNE concentrations in ram semen are substantially higher than those in humans, the results above suggest that HNE occurring naturally in seminal plasma is unlikely to have a deleterious effect on the motility or metabolism of ram spermatozoa at the sperm concentrations present in semen when ejaculated ( $1-5 \times 10^{9}$ spermatozoa $\left.\mathrm{ml}^{-1}\right)$, or diluted for artificial insemination $\left(10^{8}-10^{9}\right.$ spermatozoa $\left.\mathrm{ml}^{-1}\right)$. The lipophilic nature of HNE means, however, that locally produced HNE may remain within the sperm membrane at much higher concentrations than those diffusing into seminal plasma; and there is little information currently available on the production of hydroxyalkenals by ram spermatozoa after stressful events such as freeze-thawing. The potential effects of lower concentrations of hydroxyalkenals on the fertilizing capacity or genome of ram spermatozoa also remain to be investigated.

The authors wish to thank K. Murdoch for technical assistance and the Australian Wool Corporation for financial support (I. G. White) and the provision of a postgraduate scholarship (D. P. Windsor).

\section{References}

Aitken RJ and Clarkson JS (1987) Cellular basis of defective sperm function and its association with the genesis of reactive oxygen species by human spermatozoa Journal of Reproduction and Ferility 81 459-469

Aitken RJ and Clarkson JS (1988) Significance of reactive oxygen species and antioxidants in defining the efficiency of sperm preparation techniques Journal of Andrology 9 367-376

Alvarez JG and Storey BT (1982) Spontaneous lipid peroxidation in rabbit epididymal spermatozoa: its effect on sperm motility Biology of Reproduction 27 1102-1108

Alvarez JG and Storey BT (1984a) Assessment of cell damage caused by spontaneous lipid peroxidation in rabbit spermatozoa Biology of Reproduction 30 323-331

Alvarez JG and Storey BT (1984b) Lipid peroxidation and the reactions of hydrogen peroxide in mouse spermatozoa Biology of Reproduction 30 833841

Barber AA and Bernheim F (1967) Lipid peroxidation: its measurement, occurrence and significance in animal tissues Advances in Gerontological Research 2 355-403

Benedetti A, Casini AF and Ferrali M (1977) Red cell lysis coupled to the peroxidation of liver microsomal lipids. Compartmentalisation of the haemolytic system Research Communications in Chemical Pathology and Pharmacology 17 519-528

Benedetti A, Casini AF, Ferrali M and Comporti M (1979) Effects of diffusible products of rat liver microsomal lipids Biochemical Journal 180 303-312

Benedetti A, Comporti M and Esterbauer H (1980) Identification of 4hydroxynonenal as a cytotoxic product originating from the peroxidation of liver microsomes Biochimica et Biophysica Acta 620 281-296

Bergmeyer HU, Bernt E, Schmidt F and Stork H (1974) D-Glucose determination with HK and G6 P-DH. In Methods of Enzymatic Analysis pp 1196-1201 Ed. HU Bergmeyer. Academic Press, New York

Brambilla G, Sciaba L, Faggin P, Maura A, Marinar UM, Ferro M and Esterbauer H (1986) Cytotoxicity, DNA fragmentation and sister-chromatid exchange in Chinese hamster ovary eggs exposed to the lipid peroxidation product 4-hydroxynonenal and homologous aldehydes Mutation Research 171 169-176

Cadenas E, Muller A, Brigelius R, Esterbauer H and Sies H (1983) Effects of 4-hydroxynonenal on isolated hepatocytes Biochemical Journal 214 479487

Comporti M (1985) Biology of disease. Lipid peroxidation and cellular damage in toxic liver injury Laboratory Investigation $53599-623$

Diezel W, Engel S, Sonnichsen N and Hohne WE (1980) Lipid peroxidation products in human spermatozoa: detection and pathogenic significance Andrologia 12 167-171

Emmens CW (1947) The motility and viability of rabbit spermatozoa at different hydrogen ion concentrations Journal of Physiology 106 471-481

Esterbauer H, Zollner H and Scholz N (1975) Reaction of glutathione with $\alpha, \beta$-conjugated carbonyls Zeitung Naturforschung 306 466-470

Esterbauer H, Ertl A and Scholz N (1976) The reaction of cysteine with $\alpha, \beta$-unsaturated aldehydes Tetrahedron 32 285-289

Esterbauer H, Cheeseman KH, Dianzani MU, Poli G and Slater TF (1982) Separation and characterization of the aldehydic products of lipid peroxidation stimulated by $\mathrm{ADP}-\mathrm{Fe}^{2+}$ in rat liver microsomes Biochemical Journal 208 129-140

Ferrali M, Fulceri R, Benedetti A and Comporti M (1980) Effects of carbonyl compounds (4-hydroxyalkenals) originating from the peroxidation of liver microsomal lipids on various microsomal enzyme activities of the liver Research Communications in Chemical Pathology and Pharmacology 30 99-112

Froman DP, Amann RP, Riek PM and Olar TT (1984) Acrosin activity of canine spermatozoa as an index of cellular damage Journal of Reproduction and Fertility 70 301-308

Froman DP, Schenk IL and Amann RP (1987) Sperm-bound amidase activity as a marker for acrosomal integrity in bull spermatozoa Journal of Andrology 8 162-169

Fujihara N and Howarth B, Jr (1978) Lipid peroxidation in fowl spermatozoa Poultry Science 57 1766-1768

Fujihara $\mathbf{N}$ and Koga $\mathbf{O}$ (1984) Prevention of the production of lipid peroxide in rooster spermatozoa Animal Reproduction Science 7 385-390

Gabriel L, Miglietta A and Bonelli G (1983) 4-Hydroxynonenal effect on tubulin polymerization and colchicine binding IRCS Medical Science 11 44-45 Downloaded from Bioscientifica.com at 04/26/2023 11:03:17AM 
Gabriel L, Miglietta A and Dianzani MU (1985) 4-Hydroxynonena's interaction with purified microtubular protein Chemical-Biological Interactions 56 201-212

Griffin DS and Segall HJ (1986) Genotoxicity and cytotoxicity of selected pyrrolizidine alkaloids, a possible alkenal metabolite of the alkaloids, and related alkenals Toxicology and Applied Pharmacology 86 227-234

Gutman I and Wahlefeld AW (1974) L-(+) Lactate determination with LDH and NAD. In Methods of Enzymatic Analysis pp 1464-1468 Ed. HU Bergmeyer. Academic Press, New York

Hancock JL (1951) A staining technique for the study of temperature-shock in semen Nature $167323-324$

Jones $\mathbf{R}$ and Mann T (1973) Lipid peroxidation in spermatozoa Proceedings of the Royal Society of London Series B 184 103-107

Jones R and Mann T (1976) Lipid peroxides in spermatozoa; formation, role of plasmalogen and physiological significance Proceedings of the Royal Sociefy of London Series B 193 317-333

Jones $\mathbf{R}$ and Mann $\mathbf{T}$ (1977a) Toxicity of exogenous fatty acid peroxides towards spermatozoa Journal of Reproduction and Fertility 50 255-260

Jones $\mathbf{R}$ and Mann $\mathbf{T}$ (1977b) Damage to ram spermatozoa by peroxidation of endogenous phospholipids Joumal of Reproduction and Fertility 50 261-268

Jones R, Mann T and Sherins RJ (1978) Adverse effects of peroxidised lipid on human spermatozoa Proceedings of the Royal Society of London Series B 201 413-417

Jones R, Mann T and Sherins RJ (1979) Peroxidative breakdown of phospholipids in human spermatozoa, spermicidal properties of fatty acid peroxides, and protective action of seminal plasma Fertility and Sterility 31 531-537

Jürgens G, Lang J and Esterbauer H (1986) Modification of human low-density lipoprotein by the lipid peroxidation product 4-hydroxynonenal Biochimica et Biophysica Acta 875 103-114

Lame MW and Segall HJ (1987) In vitro effects of trans-4-hydroxy-2-alkenals on mouse liver cytochrome P-450 Chemical-Biological Interactions 62 59-74

Mann T and Lutwak-Mann C (1981) Male Reproductive Function and Semen. Springer-Verlag, Berlin and Heidelberg

Molinia, FC and Swan MA (1991) Effect of ethanol and methanol on the motility of Saccostrea commercialis sperm and sperm models Molecular Reproduction and Development 30 241-249

Paradisi L, Panagini C, Parola M, Barrera G and Dianzani MU (1985) Effects of 4hydroxynonenal on adenylate cyclase and $5^{\prime}$-nucleotidase activities in rat liver plasma membranes Chemical-Biological Interactions 53 209-217

Poli G, Dianzani MU, Cheeseman KH, Slater TF, Lang J and Esterbauer H (1985) Separation and characterisation of the aldehydic products of lipid peroxidation stimulated by carbon tetrachloride of $A D P$-iron in isolated rat hepatocytes and rat liver microsomal suspensions Biochemical Journal 227 $629-638$
Roders MK, Glende EA, Jr and Recknagel RO (1978) NADPH-dependent microsomal lipid peroxidation and the problem of pathological action at a distance: new data on induction of red cell damage Biochemical Pharmacology 27 437-443

Roubal WT and Tappel AL (1966) Damage to proteins, enzymes, and amino acids by peroxidising lipids Archives of Biochemistry and Biophysics 113 5-8

Selley ML, Mcguiness JA, Jenkin LA, Bartlett MR and Ardlie NG (1988) Effect of 4-hydroxy-2,3-trans-nonenal on platelet function Thrombosis and Haemostasis 59 143-146

Selley ML, Lacey MJ, Bartlett MR, Copeland CM and Ardlie NG (1991) Content of significant amounts of a cytotoxic end-product of lipid peroxidation in human semen Journal of Reproduction and Fertility 92 291-298

Sexton TJ (1988) Research note: influence of damaged spermatozoa on the fertility of turkey semen stored 24 hours at $5^{\circ} \mathrm{C}$ Poultry Science $671483-1485$

Shannon P (1965) The condition of diluents containing glycine and glycerol to the fertility of diluted bovine semen Journal of Dairy Science 48 1357-1361

Shannon P and Curson B (1972) Toxic effect and action of dead sperm on diluted bovine semen Journal of Dairy Science 55 614-620

Slaweta R, Wasowicz W and Laskowska T (1988) Selenium content, glutathione peroxidase activity and lipid peroxide level in fresh bull semen and its relationship to motility of spermatozoa after freezing-thawing Journal of Veterinary Medicine A35 455-460

Steel RGD and Torrie JH (1981) Principles and Procedures of Statistics. McGraw-Hill International, Singapore

Umbreit WW, Burris RH and Stauffer JF (1959) Manometric Techniques. Burgess, Minneapolis

Vishwanath R, Swan MA and White IG (1986) Effect of Triton X-100 on ultrastructure, reactivation and motility characteristics of ram spermatozoa Gamete Research 15 361-371

White IG and VogImayr JK (1986) ATP-induced reactivation of ram testicular cauda epididymal, and ejaculated spermatozoa extracted with Triton X-100 Biology of Reproduction 34 183-193

Wills ED (1971) Effects of lipid peroxidation on membrane-bound enzymes of the endoplasmic reticulum Biochemical Journal 123 983-991

Winter CK, Segall HJ and Haddon WF (1986) Formation of cyclic adducts of deoxyguanosine with the aldehydes trans-4-hydroxy-2-hexenal and trans-4-hydroxy-2-nonenal in vitro Cancer Research 46 5682-5686

Wishart GJ (1984) Effects of lipid peroxide formation in fowl semen on sperm motility, ATP content and fertilizing ability Journal of Reproduction and Fertility 71 113-118

Yanagimachi R and Teichman RJ (1972) Cytochemical demonstration of acrosomal proteinase in mammalian and avian spermatozoa by a silver proteinase method Biology of Reproduction 6 87-97 